\title{
Four generations of Quality: into the future
}

\author{
John P. Hammond
}

Technical and Marketing Manager, Starna Scientific Limited, 52-54 Fowler Road, Hainault, Essex IG6 3UT, UK

\section{Introduction}

Given the events of the last 12 months, if the COVID-19 pandemic has taught us anything, it is that we cannot predict the future and we all live in a changing and evolving World. Related to this, the recent enforced period of reflection has allowed us all to review our working environments in many aspects, not least the availability to work remotely from a given environment. As someone who has been involved with the science of analytical measurement and/or spectroscopy for the majority of my adult life, this period of reflection centred not only on the last 12 months, but importantly on the changes since I started in a Quality Assurance $(\mathrm{QA})$ laboratory many years ago.

Those of us based in the UK will have heard our Prime Minister say, and repeat many times recently, "...we will be governed by the data, and not by the dates".

The generation of data that is Fit for Purpose is inexorably linked to its production in a Quality environment, and as a derivation of the above statement one could state that:

I... we will be governed by the quality and not by the dates".

Therefore, it seems somewhat appropriate that now is a good time to review what quality means, how it has changed with time and how it has governed some

DOI: $10.1255 / \mathrm{sew} \cdot 2021 . \mathrm{a} 10$
(C) 2021 The Author
Published under a Creative Commons
BY-NC-ND licence
CC) $\$$ BY $@$ NC

key dates in an appropriate chronological timeline.

This article introduces a series of specific reviews on associated key topics described below, but first let us expand on the title and its textual components.

\section{Definition of Quality}

Use any search engine that you wish, and you'll come up with multiple definitions of the word "Quality". However, here is one generally accepted definition from Wikipedia, and which reflects its multifaceted interpretation in the English language.

In business, engineering, and manufacturing, quality has a pragmatic interpretation as the non-inferiority or superiority of something; it's also defined as being suitable for its intended use while satisfying customer expectations. Quality is a perceptual, conditional, and somewhat subjective attribute and may be understood differently by different people. Consumers may focus on the specification quality of a product/service, or how it compares to competitors in the marketplace. Producers might measure the conformance quality, or degree to which the product/service was produced correctly. Support personnel may measure quality in the degree that a product is reliable, maintainable, or sustainable."

Let us dissect this definition further and relate the statements to our Spectroscopy World.

In business, engineering, and manufacturing, quality has a pragmatic interpretation as the non-inferiority or superiority of something..."
In a purely commercial and decision and/or results driven environment such as a manufacturing QA laboratory, the quality of a product may be driven by and stated by its expected specification. This perceived or otherwise statement of quality will be discussed further in these series of articles.

-...defined as being suitable for its intended use while satisfying customer expectations..."

Or otherwise stated as "Fit for Purpose". This consideration is discussed alongside other the primary requirements in an article dedicated to explaining these key concepts.

II...Quality is a perceptual, conditional, and somewhat subjective attribute and may be understood differently by different people..."

This statement underpins the contractual considerations clearly defined in the ISO 9001 quality standard and will be expanded further in the appropriate article.

-...Consumers may focus on the specification quality of a product/service, or how it compares to competitors in the marketplace...

In a laboratory environment, the comparison of instrument system specification(s) is often the essential starting point of any purchasing decision. However, sometimes "life is never straightforward" and given the importance and/or time period that the chosen system may be in use for, this fundamental decision should be given more priority than it sometimes is. A later article in the series will discuss this further and provide some additional guidance.

I...Producers might measure the conformance quality, or degree 


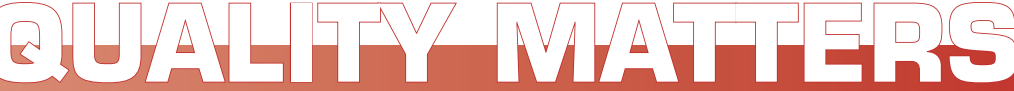

to which the product/service was produced correctly..."

Implicit within this statement, is the measurement of quality, and as and when appropriate these articles will briefly discuss the use and application of appropriate statistical tools and concepts, as the question has to be asked "how to quantify quality"?

". . Support personnel may measure quality in the degree that a product is reliable, maintainable, or sustainable."

Last, but not least, one of the ethereal considerations of quality, that one would hope is the outcome of commitment to a policy of "quality first", and which will be discussed in the final article in the series.

\section{Why "four generations of quality"?}

Having defined "quality" given the above title, an associate definition of "generation" is also in order, and again in a chronological sense, the timescale is accepted as between 20 and 35 years. It is my intention to use these generational steps as boundaries points, and reflect and review the key aspects of "quality" associated with those periods as shown below:

$1^{\text {st }}$ Generation: the years between 1940 and 1975 ,

$2^{\text {nd }}$ Generation: the years 1975 to 2000 , $3^{\text {rd }}$ Generation: the years 2000 to 2020 and

$4^{\text {th }}$ Generation: from 2021 forward.

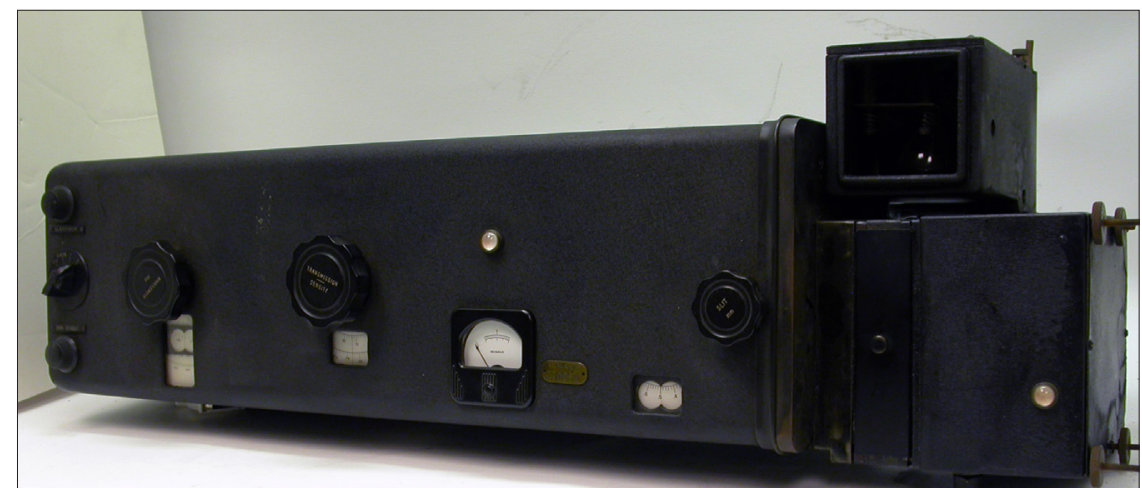

The Beckman DU spectrophotometer. Photo courtesy of the Beckman Institute for Advanced Science and Technology at the University of Illinois Urbana-Champaign

The start date of 1940 was chosen, as significantly in 1941, Beckman announced the introduction of the DU spectrophotometer, which introduced an instrumental measurement process capability to the comparison and use of visual colour science, and effectively enabled the quantitative measurement of a chemical species, by use of an associated method calibration process. Approximately 30,000 DU spectrophotometers were manufactured and sold between 1941 and 1976, and therefore, this, and other key events provides a convenient break in the chronological timeline.

From a personal perspective, my journey on the Quality path began in 1975 in a QA laboratory of a fine chemical supplier, which purely by coincidence had a DU spectrophotometer in the laboratory in which I was employed.
Therefore, the non-historical review begins in earnest at the start of the $2^{\text {nd }}$ Generation, and continues to this day.

Significantly, at the start of the $2^{\text {nd }}$ Generation, there was an awakening in all spheres of manufacturing, driven by a consumer emphasis on qualityrelated issues, powered in no small part by some health-related and well-publicised issues at that time. In the laboratory sphere, this produced the inception of several key concepts that we now take for granted, and the internationally recognised organisations associated with them.

During this period, the increased importance of standards in all aspects, and the general regulatory environment in which they are used can be shown by the fact that in 1981 a reference publication describing the current standards in use with ultraviolet (UV) spectrometry
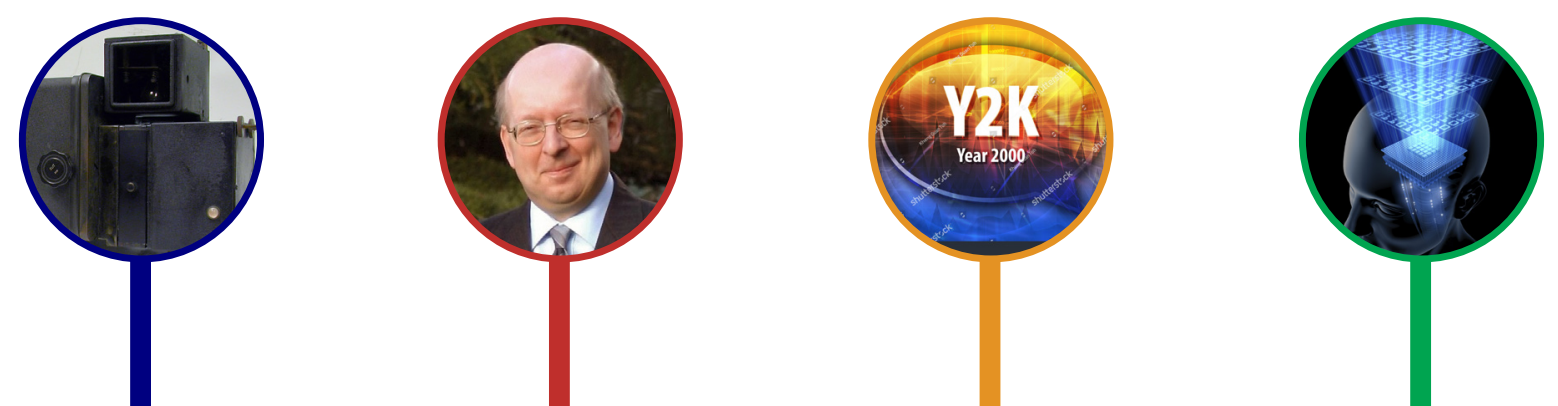

$1^{\text {st }}$ Generation

Four Generations of Quality, a chronological timeline. 
was published, ${ }^{1}$ and in 1999, this publication was reviewed and significantly updated as Standards and Best Practice in Absorption Spectrometry ${ }^{2}$ and expanded to now cover the required control in a regulated environment. Along a parallel path, the development of the ubiquitous IBM PC in 1981 began the relentless shift to use of the computer system to control instrumentation, and the related software which continues to this day.

The $3^{\text {rd }}$ Generation significantly starts in 2000, and if one considers the first two generations are associated principally with the development of the physical instrumentation, the Quality environment in which it is to be used and the software to control it; this generation revolves around the software associated with the instrument systems, and the increasing evidence of ensuring, and perhaps more appropriately, proving the control. Those of us involved with the process will not have forgotten the fear that the "Millennium Bug" engendered in our software engineers at the turn of the century, and the hours of coding and checking associated with it to ensure that systems did not stop working as the "clock struck twelve". Now fundamental in all aspects of "quality", a later article in the series on software will concentrate on the developments in the $21^{\text {st }}$ century and the control aspects of this essential science.

Clearly, we are also at the start of what is proposed to be the $4^{\text {th }}$ Generation, but already there are some key indicators to the way forward which will be discussed in the series of articles described below, using this basic chronological framework.

Mention the word quality, and immediately there is the association with "Standards", and thereby is another ambiguity of the English language, as are you referring to the control documents, or the physical reference materials used to implement them?

Take "Quality Standards" as a general term, and in addition to those described below, you could broaden the list to include for example: Environmental Quality Standards (EQS), the IATF Automotive standards, Six Sigma etc.
These standards have their own position in the science of Quality, and their exclusion from this article is in no way to deride their importance, it is just an essential admission to keep this document to a reasonable size.

In fact, evolution of the metrological language associated with this science, is also another key aspect of this topic.

Regular readers of this column over the last 20 years will be familiar with the particular aspects of these standard that have been discussed, and the article which time-stamped and initiated this process is referenced. ${ }^{3}$

\section{Article 1: this introductory article}

A short precis/abstract of the articles to come. As described above each article will discuss the key aspects of each of the past two and current $3^{\text {rd }}$ Generation, relating to the main topic area(s) of the article. Key indicators to the $4^{\text {th }}$ Generation will be mentioned, but not discussed fully until the final article in the series. The number and/ or sequence of the following articles is provided at this point in time, but if recent history with respect to COVID19 has taught us anything, it is not to attempt to predict too far into the future.

\section{Article 2: ISO 9000 and 17000 series Quality standards}

This article concentrates on the stated ISO standards and their place within the Quality environment. By definition, it discusses the role of ISO in the administration and control of these standards and their evolution and harmonisation into the standards currently in existence. In relation to these standards, the role of the ISO Technical Committee, ISO/ REMCO is discussed, and the reason(s) for its recent conversion to ISO/TC334 as part of this evolution.

\section{Article 3: ISO 9000 and}

17000 series Quality standards-their impact on the laboratory

A summary review of the two principal ISO 17000 series accreditation standards, namely ISO/IEC $17025^{4}$ and ISO $17034^{5}$ and their impact on the associated QA Testing or Calibration Laboratory. Also, how these standards have evolved and continue to be implemented. In addition, this article discusses the role(s) of the ISO 9000 series and ISO 17000 series support standards within this controlled environment.

\section{Article 4: The GxP series \\ Quality standards-their impact on the pharmaceutical laboratory}

A summary review of the GxP standards, and their impact on the associated QA laboratories within the pharmaceutical environment. Also, how these standards have evolved and continue to be implemented. In addition, this article discusses the role(s) of the International Committee on Harmonization ( $\mathrm{ICH}$ ), and the changes in pharmacopoeial requirements within this controlled environment.

Article 5: Key quality indicators and their impact on the associated environments Specific quality indicators are in use in both the ISO and GxP environments, and how these are defined and used are discussed. In addition, the crossover, with respect to these specific concepts, is investigated by the use of the adoption/exchange in each environment, e.g., Qualification from GxP being implemented in ISO labs, and vice versa, the use of Expanded Uncertainty Budgets from ISO being used in updates to pharmaceutical standards etc.

Article 6: Regulatory changes, and their influence on the quality of data being produced by instrument systems Having now defined the regulatory framework, and documentary standards associated with the environment, this article introduces the key concepts of Control Space, "Fitness for Purpose", "Proof of Control" and Data Integrity, and how this has influenced the design and manufacture of instrument systems. 
Article 7: Regulatory changes, and their influence on the control software implemented on instrument systems

A software-specific article which discusses the demands and/or requirements of the key concepts discussed in the previous article, and how these requirements can be implemented. Also discussed are the "pitfalls" to avoid.

Article 8: Changes and adoption of existing and new spectroscopic techniques to meet new requirements This article discusses the increased use or existing and/or new spectroscopic techniques, and the associated challenges that this Quality environment posses. Techniques discussed include, for example the increased use of fluorescence and/or Raman and near infrared spectroscopies in application areas. In addition, practical system hardware configurations/implementations are discussed.

Article 9: Round-up and future[s], with informed projection into the next 20 years

This final article in these series discusses the pathway into the future and uses, where possible, very recent new publications and/or changes in the discussed areas. Thereby, the final section also proposes some "blue sky" projections as we move forward into the next generation.

\section{Ready to start?}

"All the World's a stage, / And all the men and women merely players."

William Shakespeare, As You Like It, Act II, Scene VII, Line 139

So, "the play is written, the stage is set, ... all we need now are the players?"

Therefore, in the next article in this series, we will begin our review of this cast of players, by discussing the International Organization for Standards (ISO) and their role in establishing Quality in Spectroscopy; both from a chronological and a personal perspective.

\section{References}

1. A. Knowles and C. Knowles, Standards in Absorption Spectrometry. Springer (1981). ISBN: 978-0-412-22470-6

2. C. Burgess and T. Frost (Eds), Standards and Best Practice in Absorption Spectrometry. Blackwell
Science (1999). ISBN: 0-63205313-5

3. J.P. Hammond, "New certified reference materials for the determination of photometric accuracy in UV spectrophotometry", Spectrosc. Europe 13(4), 10 (2001). https://doi. org/10.1255/sew.2001.a 1

4. ISO/IEC 17025, General Requirements for the Competence of Testing and Calibration Laboratories. International Organization for Standardization (ISO), Geneva, Switzerland (2017). https://www. iso.org/standard/66912.html

5. ISO 17034, General Requirements for the Competence of Reference Material Producers. International Organization for Standardization (ISO), Geneva, Switzerland (2016). https://www.iso.org/standard/29357.html

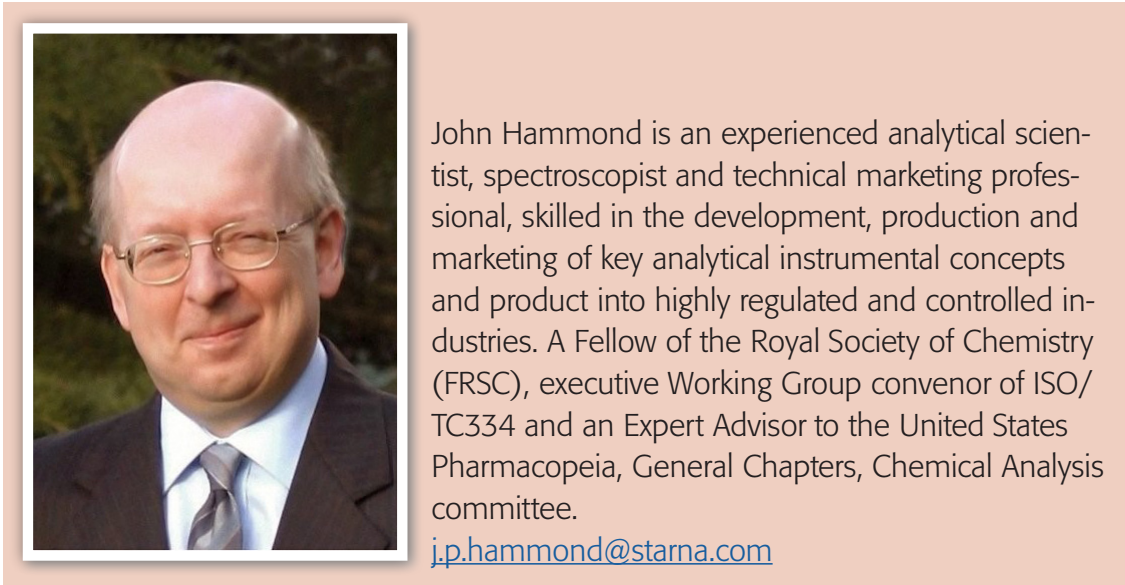

